\title{
Court of Last Appeal - The Early History of the High-fat Diet for Diabetes
}

\section{George Henderson*}

Human Potential Centre, Auckland University of Technology, New Zealand

*Correspondence author: Henderson G, Research associate, Human Potential Centre, Auckland University of Technology, New Zealand, Tel: +64 9-921 9999; E-mail: puddleg@gmail.com

Received date: Aug 02, 2016; Accepted date: Aug 18, 2016; Published date: Aug 25, 2016

Copyright: (C) 2016 Henderson G. This is an open-access article distributed under the terms of the Creative Commons Attribution License, which permits unrestricted use, distribution, and reproduction in any medium, provided the original author and source are credited.

\begin{abstract}
The first low carbohydrate diets for diabetes, which were introduced in the 18th century, were not high fat diets so much as high protein diets. By the late nineteenth century a consensus had begun to appear in European studies that a higher fat and lower protein intake was more tolerable. Frederick Allen confirmed this in animal studies, but the diet he introduced into clinical practice in 1914 restricted fat, protein, and total calories, becoming in extreme cases a starvation diet with the deadly side effect of "inanition". Interpreting Allen's research in light of the studies in chemical metabolism of Rollin Woodyatt, Louis "Harry" Newburgh, with Phil Marsh, dared to increase fat in the diets of diabetic patients at the University of Michigan Hospital in 1918, with gratifying results which were published in 1920. A dispute followed between Newburgh and Allen's disciple Elliott P Joslin; Woodyatt, Russell M Wilder, Karl Petren and others confirmed Newburgh's results by experimentation and by 1924 Joslin too was reporting the higher fat diet's ability to extend life in diabetics untreated with insulin. However, a dispute between Joslin and Newburgh about the long-term safety of the high fat diet continued long into the insulin era.
\end{abstract}

Because the debate about the effect of the high-fat diet in the tabula rasa of the pre-insulin era only lasted a few years, and rigorous research into the question was largely limited to the state of Michigan, medical history has paid little attention to the fact that the question of what is the "optimum", or default, diet for diabetes, based on physiological principles as well as clinical practice and experiment, was at one time almost settled. This historical review paper summarises the early clinical researches of Newburgh et al. into the effects of the high-fat diet in the treatment of diabetes, with a particular focus on events in Michigan between 1918 and 1930.

Keywords: High fat; Appeal; Diabetes; Glucose

\section{The First Low-carbohydrate Diet for Diabetes}

In Two Cases of the Diabetes Mellitus, Rollo and Cruickshank described the treatment of two patients suffering from glycosuria, polyuria and polydipsia with a combination of organic and inorganic salts and a diet restricted in vegetable food, and made largely of meat and fat [1]. This was based on the observation that, while both animal foods and vegetable foods are nutritious and will support life, glucose, found in the urine of patients with diabetes and therefore obviously connected to the disease, can be found in large quantities in vegetable foods but only in trace amounts in meat and fat. The diet was effective for one of Rollo's patients, but not the other. Redfearn subsequently published a report of the successful application of Rollo's method in his own patient [2] and Rollo's supporter John Latham published many case studies of the diet in his 1811 book Facts and Opinions Concerning Diabetes [3]. Rollo's method seems to have become widely disseminated; circa 1830 the American adventurer Josiah Harlan, who had taught himself medicine from a popular encyclopaedia, prescribed an animal matter diet to a client in the Punjab, with what results we do not know, according to Ben MacIntyre's life of Harlan, The Man Who Would be King [4].

The inconsistent response to the diet seen in Rollo's first two cases, and in the cases of Latham, can be explained by its high protein content. In the later researches of Woodyatt and others, protein has a glucose value of $58 \%$, due to a high proportion of gluconeogenic amino acids. Hadden gives an analysis of Rollo's diet for patient 1, Captain
Meredith, as supplying $160 \mathrm{~g}$ carbohydrate, $136 \mathrm{~g}$ protein and $135 \mathrm{~g}$ fat [1]. Thus only $50 \%$ of the energy from this diet is in the form of the nutrient, fat, which has the lowest requirement for insulin; nor is the diet as low in carbohydrate (from bread and milk, and later, when Captain Meredith returned to Ireland, potatoes) or as permissive with regard to non-starchy vegetables as modern thought would recommend. Captain Meredith lived another 15 years after adopting Rollo's diet, dying in Newfoundland at the age of 49 - according to Hadden, death was probably due to macrovascular complications.

\section{Nineteenth Century Developments}

Rollo's approach was improved upon by subsequent European clinicians. In the third of a series of lectures on diabetes by Lauder Brunton, published in the British Medical Journal in 1874, a diet is recommended: "consisting of nitrogenous food, such as butcher-meat, fish, eggs, and soups. Fat (which does not contribute in the least to the formation of sugar) may be given in all its forms, such as cream, butter, cheese, and oil. Spinach, lettuce, and cresses may be freely used, but celery and radishes only sparingly; while potatoes, carrots, parsnips, turnips, peas, French beans, cabbage, Brussels sprouts, cauliflower, brocoli, asparagus, seakale, and fruit of all kinds, both fresh and preserved, should be avoided, with the exception of nuts and almonds" [5]. A starch-free gluten bread is suggested as a replacement for bread. The diet described is very low in carbohydrate, but the ideal proportion of protein to fat is not discussed. In 1875 Arnaldo Cantani in Italy published the results of clinical treatment of 84 cases of diabetes with a diet of meat and fat, which quickly produced dramatic reductions in 
glycosuria [6]. Cantani's dietary regime involved periods of energy restriction, however the German physiologist Wilhelm Ebstein cites Cantani as an authority for the use of pure fat in diabetic diets. In 1892 Ebstein published his comprehensive review of the literature on diet, lifestyle, and diabetes, Über die Lebensweise der Zuckerkranken, which includes the statement that "up to about 200 grams of fat is well tolerated by the majority of diabetics" [7]. Also in 1892, Ebstein's book on Corpulence and its Treatment on Physiological Principles, which contained brief summaries of his findings on fat and diabetes, was translated into English [8]. In this book and his subsequent work On the Regimen to be Adopted in Cases of Gout Ebstein discussed experimental evidence on the metabolism of protein and the desirability of limiting both protein and carbohydrate, and increasing fat, in the treatment of metabolic diseases [9].

\section{The Naunyn Era 1898-1914}

In 1898 Bernhard Naunyn published his classic treatise Der Diabetes Mellitus wherein he "counteracted the prevailing opinion of the supposed benefit of a high-protein diet in the treatment of diabetes mellitus"[10]. This work appears to have been highly influential in the U.S.A. Elliott Joslin in 1933 described what he called the Naunyn Era, in these words; "Fat was practically unlimited and the patients were always urged to take more fat. At one time my patients put fat in their soup, their coffee and matched their eggs with portions of fat of equal size. The carbohydrate was kept extraordinarily low with the result that sixty per cent of the cases died of diabetic coma. Yet we must not be too hasty in drawing conclusions; Case No. 8, whose diabetes began at 60 , lived out her full life expectancy and so did her sister, Case No. 899 whose diabetes commenced when she was 83 years old. If a diabetic lives as long as his average neighbor that is a triumph" [11]. Joslin had earlier stated that mortality in Professor Naunyn's care was $28.2 \%$ "which was the same, as far as I can determine, for the city of Boston for 1915. The period of my own activity has been later, and so more favourable; perhaps my cases have been less severe, and this may explain first, why but 17 per cent. of my own cases have died during the first year of the disease, and second, the more encouraging feature that 95 per cent of those living have already gone beyond this period" [12]. In Joslin's words we see the difficulty, which we will meet with again, of comparing two populations who may differ in the severity of disease, in the prevalence of complicating factors such as epidemic infectious diseases, and in the opportunity for close supervision and compliance with doctor's orders.

\section{The Allen Era 1914-1922}

Following the publication of Frederick Allen's researches in 1913, the clinical benefits of which Joslin enthusiastically promoted, came what Joslin called the Allen Era, 1914-1922, with "control of calories, but carbohydrate low and fat still high. With this simple but fundamental expedient coma as a cause of death fell to 40 per cent and in well-regulated hospitals seldom developed de novo." [11] The essential distinction between the Naunyn and Allen methods was the use of fasting in the latter to reverse glycosuria ("desugarization") and prevent ketoacidosis. However, calorie restriction in some cases lasted long enough to produce inanition and death from starvation, as Mazur describes [13]. Yet this was not the whole story - Joslin describes seeing a patient of Allen's in 1931 who "had lived for 15 years on a low carbohydrate diet, C 60, P 90, F 133 [i.e. $1800 \mathrm{kcal}$ ] without insulin and yet to my astonishment he showed a normal cholesterol. I urged him to take a higher carbohydrate content of the diet and, if necessary to utilize it, insulin, but he refused because he said he was contented and never missed a day's work. In 1932 I saw him again and his cholesterol was 219 milligrams and his diet unchanged and his condition equally good" [11]. The macronutrient and calorie intake in this example is in fact similar to the average that Westman and Yancy abstracted from the hospital records of the 48 adult patients in Allen et al's 1919 case series; C 38.7 g, P 85.3 g and F 156.4 g, to a total of 1956 $\mathrm{kcal} /$ day [14] (Figure 1).

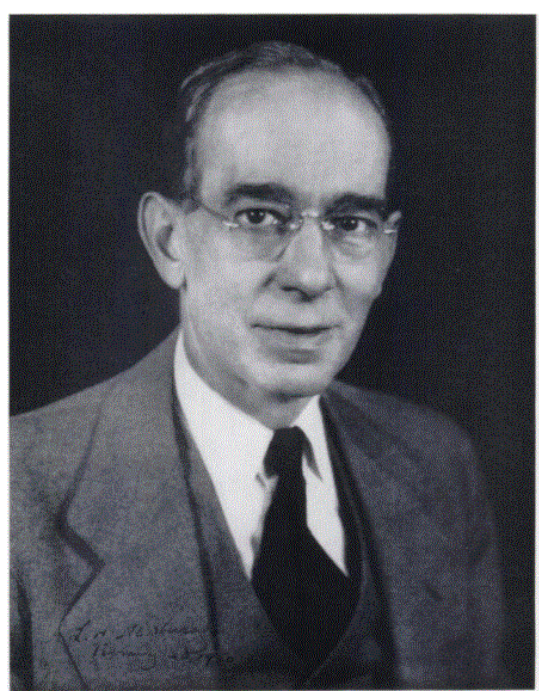

Figure 1: Frederick Lewis Allen in 1932.

\section{The "Michigan Diet" of Newburgh and Marsh: The First Paper}

Louis "Harry" Newburgh began his lifelong career in clinical investigation in Boston, and in 1916 accepted an invitation from the University of Michigan Medical School in the city of Ann Arbor to work full time in medicine, but with ample opportunity for clinical research [15]. Appointed Assistant Professor of Internal Medicine in 1916 at the age of 33, the following year Newburgh became Acting Head of the Department of Medicine, a role which he held till 1922 when he was appointed Professor of Clinical Investigation, a unique title which only Newburgh has held at Michigan University. Newburgh took a particular interest in diabetes and other metabolic diseases seen in the University Hospital, which was, as he termed it "a court of last appeal" where patients who did not respond to "simple diabetic measures", or who presented complicating features such as infections, injury, cancers, poverty, or mental illness, were admitted. Though inspired by Allen's starvation diet success, Newburgh, beginning on March 1 1918, "dared to ignore the belief concerning the danger of fat in the diet of diabetics" with the aim of avoiding the dangers of inadequate energy, excess carbohydrate, or excess protein. Allen himself had said, based on his early researches, that "fat is not to be feared in the diet of diabetics". But whereas Allen and Joslin fasted patients to reverse glycosuria, before allowing a calorie-restricted diet that was relatively high in protein, Newburgh adopted this routine procedure; "When a patient enters the clinic, he is placed on a diet containing from 900 to 1,000 calories, of which about $90 \mathrm{gm}$. is fat, 10 $\mathrm{gm}$. is protein and $14 \mathrm{gm}$. is carbohydrate. After the patient has been sugar free for one or two weeks, his diet is increased to about 1,400 
calories, of which $140 \mathrm{gm}$. is fat, $28 \mathrm{gm}$. is protein and from 15 to 20 gm. is carbohydrate. In the cases of small individuals this diet is sufficient for prolonged use, and some of them are discharged with instructions to continue it. For larger persons, after another period of trial, a second increase is made, reaching 1,800 calories, containing 170 gm. of fat, from 30 to $40 \mathrm{gm}$. of protein, and from 25 to $30 \mathrm{gm}$. carbohydrate. Further additions up to 2,500 calories may be made to suit individual cases." [16] The 1920 paper, The use of a high fat diet in the treatment of diabetes mellitus, co-authored with Phil L. Marsh, who had joined Newburgh in 1919, described the treatment of 73 cases, most with severe diabetes, of whom four died from causes unconnected to the diet (including one patient who "refused to limit herself to the diet, and went into coma after eating a bag of oranges brought by a relative"). No adverse effects of the high-fat diet were seen and "unexpectedly enough, acidosis, even though marked, existing at entrance, invariably cleared up under our treatment". Ketonuria was assayed with the ferric chloride reaction, which detects acetoacetate but not beta-hydroxybutyrate. The case series in this paper included a 7 -year-old boy, whom the diet kept free from acidosis at an energy intake of $1425 \mathrm{kcal} /$ day. The ratio of $0.66 \mathrm{~g}$ protein per kilo of body weight was sufficient to maintain nitrogen balance (the similarity of this figure to the average of $0.65 \mathrm{~g} / \mathrm{Kg}$ obtained from a 2003 metaanalysis of nitrogen-balance experiments attests to the accuracy of Newburgh's calculations) [17] Oil in mayonnaise, butter, 40\% cream, and bacon are the main sources of fat in the menus provided, eggs, meat, chicken, and fish are the sources of protein, and a variety of nonstarchy vegetables, plus tomatoes, supplies the carbohydrates (these diabetic menus are unusual for their day, or perhaps any day, in not supplying any bread or sugar whatsoever. The oil used in mayonnaise is unknown, but was likely to have been either olive or cottonseed oil). In this 1920 "first paper" Newburgh and Marsh pointed out that their findings were preliminary, and indeed a further two papers on the same population, as well as several subsidiary investigations, were to follow in subsequent years.

\section{Newburgh and Marsh: The Second Paper}

Newburgh was a pioneer of experimentation, insisting on careful quantification of all biological parameters at a time when much of medicine was still simple pathological and clinical description. In his position he had the help of capable assistants some of whom, like Herbert Ratner of Salk vaccine fame, later became well-known in their own right, and the use of advanced laboratory facilities, including, at a later date, a metabolic chamber of his own design [15]. Whereas the first high-fat diet paper had used glycosuria as one measure of diabetes control, the second paper, published in June 1921, investigated the effect of the high-fat diet on blood sugar [18]. Results were presented from the 45 cases in which blood glucose measurements were "sufficient to permit drawing conclusions concerning the effect of the diet upon glycemia", including 5 cases, two of whom suffered from serious complicating diseases (cancer, and syphilis) in which blood sugars did not reach a satisfactorily low level. Blood glucose in the controlled cases varied between 0.06 to 0.130 percent (60 to $130 \mathrm{mg}$ / dL).

In 1922 Marsh and Newburgh, with Holly, also published a detailed investigation of nitrogen requirements in those on the high-fat diet [19]. Nitrogen intake was calculated from the food tables of Atwater and Bryant, and output in the urine and stool was quantitatively determined by the Kjeldahl method, a process described by Newburgh's biographer Horace Davenport as a "tiresome task" [15].
Because of the "difficulties in the way of collecting specimens from women", the subjects were 12 male patients between the ages of 18 and 80. Besides nitrogen intake and output, repeated measurements of ketone bodies and glucose in urine, and blood glucose and lipids, were also made for all subjects. This paper concludes "1. Nitrogen balance can be established in the diabetic according to the laws applicable to the normal subject provided his total caloric requirement can be satisfied. This implies that he can burn enough glucose to metabolize fat. Diabetics who cannot burn this small amount of glucose are extremely rare. 2. Protein metabolism above the minimal is undesirable in the diabetic because of (1) the great glycogenic property and (2) the large specific dynamic action of protein. Excessive protein metabolism results from a diet containing either too much protein or too few total calories."[19] Thus the Newburgh and Marsh diet, by supplying calories from fat in amounts adequate to spare protein, and by avoiding an excess of protein or glucose, limited gluconeogenesis and inhibited glycosuria and ketonuria. The exact hormonal and metabolic mechanisms that regulate such an effect in the insulindeficient state remain to be fully elucidated.

\section{Woodyatt Tests the High Fat Diet}

Rollin Turner Woodyatt was by the 1920s the doyen of clinical metabolic chemists, having investigated the disposal of the ketone bodies as early as 1910. In August 1921 he published a review of the experimental literature relating to fasting and high-fat feeding together with the results of an experiment of his own designed to test the Newburgh and Marsh diet. He concluded; "Granting that a diabetic patient may suffer from obesity as well as diabetes-that he may have two different metabolic defects; or granting that at times it might seem desirable to starve for other conditions besides diabetes. In such cases fasting would be rational, if it would improve the general condition. But for diabetes itself, and particularly for diabetes associated with undernutrition, why for the purpose of desugarization should the patient be compelled to draw from his tissues the fat that he might draw from a diet, especially if in drawing from his tissues he lowers his fat reserves to the extent that he increases his protein losses?" The catabolism of fat on a low carbohydrate diet is the same whether fat is fed or not, but the catabolism of protein increases when fat is depleted, and this increased supply of gluconeogenic amino acids elevates glycaemia, with the increasing risk of acidosis and coma consequent on glucosuria. It was Woodyatt's equating of fasting metabolism with the effects of the Newburgh and Marsh diet that is said to have inspired Russell M Wilder to test the effects of a ketogenic diet in patients with epilepsy, beginning in 1921 [20,21]. It is notable that the ketogenic epilepsy diet defined by Wilder is not significantly different from the anti-ketoacidotic diabetes diet of Newburgh and Marsh; Wilder considering that the appearance of up to 20 grams of ketone bodies per day in the urine was consistent with the good management of diabetes [22]. Thus the confusion between ketosis and ketoacidosis that we sometimes encounter today was clarified in the early 1920s, before the introduction of insulin, when diabetic ketoacidosis was still the most common cause of death among those with diabetes. However, it may be wondered whether the use at Michigan of the ferric chloride test, which is specific for acetoacetate, fortuitously permitted these researchers to overlook the presence of the benign degree of ketonuria associated with carbohydrate restriction [23].

In January of 1923 Marsh and Waller published a report of 12 case studies in which patients with diabetic hyperlipemia were treated with the high fat diet, finding that in all 12 cases, "there was no increase in 
the lipoid content of the blood during the periods of observation, and of much greater significance, that in the patients in whom a hyperlipoidemia existed when they first came under observation, the total fat fell to approximately normal levels", concluding that "It is certainly very strong evidence that the prevalent assumption which postulates that diabetic hyperlipoidemia is dependent on the excessive ingestion of fat is unwarranted." [24].

\section{Newburgh and Marsh; The Third Paper}

The third Newburgh and Marsh paper, Further observations on the use of a high fat diet in the treatment of diabetes mellitus, published in April 1923, summarised the clinical investigations of the four years since Newburgh began treating patients with the high-fat diet, and also supplied a clinical audit of the hospital's treatment of diabetes over that period [25]. Results were reported under 6 headings: (1) glycosuria; (2) acidosis; (3) nitrogen balance; (4) lipemia; (5) the general condition of the patient, and (6) the effect of treatment on glucose tolerance and expectation of life. Results from 190 patients with diabetes who had entered the hospital by that date were presented. "Of these, six entered the hospital in coma or in extremis from other causes, and died either before treatment could be inaugurated or before it could significantly affect the metabolism. Eight others remained but a few days, and left against our advice when they found that we had nothing to offer except diet in place of the curative drug or operation that they had expected. None of the remaining 176 diabetic patients failed to become sugar free, and all of these were discharged without glycosuria on a maintenance diet." Among the cases detailed was that of a 3-year-old boy (case 1), whose glycosuria and ketonuria resolved in 11 days. "At present, he is receiving $30 \mathrm{gm}$. protein, $115 \mathrm{gm}$. fat, $17 \mathrm{gm}$. carbohydrate and 1,225 calories, which allows him 93 calories per kilogram of body weight. He is slowly gaining in weight and has added one-fourth inch to his height." The records of two patients "show clearly that some diabetics who could not be made sugar free by starvation may be made so by a high fat diet yielding about 950 calories". Under heading 2, acidosis, freedom from ketonuria, ketoacidosis and diabetic coma in patients typically prone to the syndrome, yet eating what would be considered a ketogenic diet today, was still notable, as in the first paper. "Not only does acidosis not develop in patients who are living on this diet, but it is a fact that all our patients showing at admission an acidosis short of coma rather promptly lost their acidosis while taking the high fat diet". The results of the separately published experiments on nitrogen balance (3) and lipemia (4), mentioned above, are summarised. With regard to the general condition of patients (5), patients who had previously been desugarized by fasting who were later made sugar free by the Newburgh and Marsh diet volunteered that that "the earlier fasting method had left them in a state of exhaustion and extreme weakness and that they were astonished at their strength after they had become sugar free at our hands". On the high-fat diet, patients had sufficient energy to return to their normal occupations, whereas those patients who survived the starvation diets were sometimes bedbound. Two deaths from ketoacidosis or exhaustion due to fasting had been reported by Joslin and two cases of death subsequent to fasting prior to admission had occurred at Michigan, but there were no deaths in patients being desugarized by the hypocaloric induction phase of the high-fat diet. With regard to heading 6), the effect of treatment on glucose tolerance and life expectancy, Newburgh and Marsh state that "In our whole series we have seen no evidence of loss of tolerance in a patient who has adhered to the diet and, therefore, we have no reason for believing that downward progress is an accompaniment of a maintenance diet." Newburgh and Marsh carefully list the confounding factors that bedevil statistical comparisons of life expectancy between any two diabetic populations, including differences in social status, in the treatment of patients prior to admission, in the percentage of juvenile cases, and in the incidence of complicating diseases, including mental illnesses. Michigan Medial School Hospital, as a "court of last appeal" where the most difficult cases were admitted, was thus at a disadvantage when compared with most other practices, but a statistical comparison with Allen's, Williams', and Joslin's separate published records was not unfavourable. "Joslin has pointed out that coma as a cause of death has decreased from 68 per cent, of his fatal cases treated before 1914 to 55 per cent, since he has employed fasting and severe undernutrition. This he cites as evidence of improvement in treatment. It is, therefore, interesting to note that in our relatively small series of fatal cases, only 27 per cent have died in coma." [25].

\section{Unjustifiable Interference - The Debate with Joslin}

In 1924 Wilder published in the NEJM an enquiry into The 'Optimal' diet for Diabetic Patients informed by his researches on the ketogenic diet for epilepsy, stating that "when the ratio is as high as 3:1 and the daily oxybutyric acid excretion is 20 gm, no actual acidosis develops, indicates that when the ratio is held below 2:1 as in our clinical diets, a considerable margin of safety is secured." [22] A discussion followed between Russell Wilder, Karl Petren (who had pioneered a regime similar to Newburgh's in Sweden), Seale Harris (the originator of the concept of hyperinsulinaemia as a causal factor in diabetes), Elliot Joslin and others. Joslin discussed the high-fat diet thus; "Dr. Woodyatt has explained the manner in which more fat can be given safely than formerly. This has added two years to the lives of our patients. One must give as much carbohydrate as one can, and as much fat as one needs for weight while keeping the patient sugar free, giving at the same time enough (1 gm. per kilogram of body weight, more or less) protein for nitrogenous equilibrium." This is an imperfect summary of the methods we have discussed, allowing for more carbohydrate and protein, but can certainly be taken as an endorsement of what Joslin termed the "Michigan Diet"[22].

Despite this earlier support, Joslin would publish, in Ideals in the Treatment of Diabetes and Methods for Their Realization (1928), what amounted to an attack on the high fat diet, writing that "restriction of fat promotes tolerance of carbohydrates, that even a few units of insulin are advantageous, and that a diabetic discovered early and not damaged by a low-carbohydrate, high-fat diet is an ideal subject for treatment". [26] Joslin blamed a high death rate from atherosclerosis among contemporary diabetics on high-fat diets, citing another doctor's autopsy report. However this patient had gained $76 \mathrm{l} 1 / 2 \mathrm{lbs}$ before his death and it is not clear whether he was using insulin, nor how the diet was constructed (there are no references in the published version of Joslin's paper). Neither is Joslin consistent in placing the blame on the high-fat diet; "Without such treatment as this patient received, in the decade before the discovery of insulin, undoubtedly he would have died, but who of us believe with the evidence now available that if in the earlier years when the diet was restricted in carbohydrate, moderate undernutrition had been continued and obesity avoided, such excessive arteriosclerosis would have developed?" In modern times it is unusual, but not impossible, for patients on lowcarbohydrate, high-fat diets to gain weight, and it is generally accepted that such a diet tends to result in a spontaneous decrease in energy intake [27]. 
Newburgh's response to this criticism emphasised that Joslin had placed most weight on a case of which he had no direct experience, and that Joslin had seemingly confused the effect of the high-fat diet with the effect of over-nutrition.

"It needs to be emphasized that the low protein, low carbohydrate, high fat, maintenance diet, is the inevitable result of the application of the laws of nutrition to the special metabolic problem of the diabetic. With this simple fact in mind, we can not avoid regarding Joslin's recent adverse criticism of this dietetic procedure as an unjustifiable interference with a method that is working well. He finds that $47 \%$ of his 609 diabetic deaths since the introduction of insulin were due to disease of the arteries (we refrain from questioning how many of these diagnoses were confirmed by autopsy, and how much this incidence of arterial disease exceeds that of a similar age group from the general population). According to Joslin the prevention of arteriosclerosis is favored by reduction of weight to the normal level. Advice that we heartily accept. But we are incapable of finding any sound basis for the statements that 'The avoidance of a high fat, low carbohydrate diet is another preventive influence." [28] Newburgh's defence was to be supported by later research carried out at Ann Arbor into the effect of the low-carbohydrate, high-fat diet on serum cholesterol and the association between cholesterol and atherosclerosis [29].

\section{Later Experiments - Reversing Type 2 Diabetes}

In 1935, Newburgh was joined by Jerome Conn. Their research focussed on cases of adult diabetes associated with obesity and overweight - what we would call type 2 diabetes today. Conn and Newburgh noted in 1937 that synthesis of glycogen was impaired in overweight adults with diabetes, resulting in hyperglycaemia, and that hepatic glycogenesis was normalized in 8 patients restored to normal weight with a calorie-restricted diet [30]. This research was conducted in a respiration chamber constructed by the University to Newburgh's own specifications [31]. They subsequently reported in 1939 that they were able to restore normal glucose tolerance in almost all of 21 overweight patients who were able to regain a normal weight by following a calorie-restricted diet. "After the weight of these patients has been reduced to normal by simple underfeeding, they remain aglycosuric, do not become hyperglycemic when they are placed on maintenance diets containing $300 \mathrm{gm}$. of carbohydrate and exhibit normal dextrose tolerance curves. There is an occasional exception to this rule, but more than 90 per cent of the patients respond in this manner... Recurrence of the obesity is capable of reproducing the hyperglycemia and the delayed utilization of dextrose. Subsequent reduction of weight again corrects the disturbance in the metabolism of carbohydrate." [32]

In 1942 Newburgh reported results from 62 patients, average age 52 years, who were about $40 \%$ overweight and diagnosed by the presence of hyperglycaemia, glycosuria and one or some of the usual diabetic symptoms. Of 47 patients whose weight was reduced by amounts up to $76 \mathrm{lb}$., 36 showed a return of the blood sugar curve from diabetic levels to normal levels. Only 6 patients failed to respond to weight loss by improvement in sugar tolerance. Newburgh believed that such hyperglycaemia, responsive to weight loss, was a manifestation of obesity and not of true diabetes [33]. Thus Newburgh and Conn supplied early evidence for a modern paradigm - the reversal or remission of type 2 diabetes by dietary restriction, weight loss, or bariatric surgery [34].
In these studies it was necessary to give $300 \mathrm{~g}$ carbohydrate per day to ensure the accuracy of the OGTT, and the calorie-restricted diet used was not a low-carbohydrate diet.

It is notable that Newburgh and Conn distinguished what is now known as type 2 diabetes by this response to weight loss, whereas Himsworth in the same period was defining it as a condition of insulin resistance based on the difference in response to insulin [35].

\section{Newburgh Remembered in the Modern Era}

Herbert Ratner and Dorothy Smith-Ratner were research assistants under Newburgh in the Division of Clinical Investigation at the University of Michigan from 1934 to 1936. In 1994, in response to the publication of a feeding study of a high-fat (high MUFA), carbohydrate restricted diet for NIDDM in the JAMA, [36] they described Newburgh's protocol of sixty years earlier.

"Dr Newburgh was a pioneer in the preinsulin development of a high-fat diet for the control of diabetes mellitus, a diet he carried over into the postinsulin era. Though experience taught [Newburgh] that most diabetic children require insulin to permit a diet adequate for really normal growth. Three out of every four adult diabetics treated in the clinic could tolerate a satisfactory diet of the high-fat type without insulin. Newburgh's 1500-calorie skeletal diet included $134.85 \mathrm{~g}$ of fat derived from eggs, bacon, $32 \%$ cream, and butter. Newburgh and MacKinnon devoted six pages to whether this high-fat diet contributed to hypercholesterosis and arteriosclerosis in diabetic patients and answered in the negative. One passage stated that "eggs, which contain more cholesterol than any other common food, have little influence on the blood cholesterol." They wrote that diets containing $70 \%$ of their calories in fat had no effect on the cholesterol level. In contrast they found that overnutrition caused high cholesterol levels.

Dr Newburgh's preinsulin and postinsulin dietary control of NIDDM was a tribute to his meticulous application of nutritional knowledge. He once remarked to us that the discovery of insulin was a severe setback to the advancement of the science and art of nutrition. How prophetic he was" [37].

\section{Conclusion}

The debate between Newburgh and Joslin was one of the contrasting clinical impressions of two first-class clinicians, without the benefit of data from a randomized controlled trial. Neither party was, in clinical practice, sufficiently dogmatic for the contrast to be an absolute one, however Newburgh was, as well as a clinician, a clinical investigator par excellence, capable of recording and analyzing clinical data with more precision than Joslin, with the benefit of state-of-the-art laboratory techniques and an extraordinarily diligent team of researchers. Newburgh also, in the early 1920's, profited greatly from the rigour with which Woodyatt, Wilder, and others independently tested the Newburgh and Marsh diet in small experiments. Ultimately, Newburgh and Marsh's dietary prescription was shown to be constructed on sound physiological principles, which served Newburgh's patients well for the rest of his career and which continue to be productive of benefit today. Joslin's concerns were born of a wider-ranging curiosity and his anxiety to take into account anything that might help or harm his patients. Joslin eventually seems to have accepted that Newburgh's arguments were persuasive, without ever really putting his own doubts to rest. Newburgh notoriously did not suffer fools gladly, and if his remarkable investigations seem to have 
been written out of U.S. diabetes history, it may well be that such history was largely written by Joslin and his supporters.

The researches of Newburgh et al. are the most scientifically advanced, conscientiously performed, and intelligently analyzed clinical investigations we will ever have into the effects of diet on a population suffering from decompensated diabetes in a world without insulin. This experiment can never be recreated and modern research into the same question shows how well its results have withstood the passage of time and the improvement of scientific techniques; it would be, in our opinion, a tragic mistake to regard this research as obsolete or irrelevant to modern questions around diabetes and diet.

\section{References}

1. Hadden DL (1998) Food, growth and time. The 4th Arnold Bloom Lecture, presented at the British Diabetic Association Conference, Bournemouth, UK-October 1997. Pract Diab Int 3: 15.

2. Redfearn R (1799) A Case of the Diabetes Mellitus, which terminated in a complete, and, as far as can be judged from apparent Circumstances, a permanent Cure, by Medicines, abstracting Oxygen from the System, and a Diet consisting totally of Animal Matter. The Medical and Physical Journal 4: 21-28.

3. Latham J (1811) Facts and opinions concerning diabetes. John Murray, London.

4. Macintyre B (2004) Josiah the Great: the true story of the man who would be king. London: Harper Perennial 15: 107-120.

5. Brunton TL (1874) Lectures on the Pathology and Treatment of Diabetes Mellitus. Br Med J 1: 221-224.

6. Cantani A (1875) Researches on Diabetes Mellitus 2: 12-19.

7. Ebstein W (1892) Über die Lebensweise der Zuckerkranken. Wiesbaden: J.F. Bergmann 12: 15-20,

8. Ebstein W (1892) Corpulence and its treatment on physiological principles London: $\mathrm{H}$. Grevel 2: 12-16.

9. Ebstein W (1885) On the Regimen to be Adopted in Gout. Translated by Scott J, Churchill A

10. No authors listed (1969) Bernhard Naunyn (1839-1925), clinician, teacher, scientist. JAMA 208: 1182-1183.

11. Joslin EP (1933) Fat and the diabetic NEJM 209: 519-528.

12. Joslin EP (1916) The treatment of Diabetes Mellitus. Can Med Assoc J 6: 673-684.

13. Mazur A (2011) Why were "starvation diets" promoted for diabetes in the pre-insulin period? Nutr J 10: 23.

14. Westman EC, Yancy WS Jr, Humphreys M (2006) Dietary treatment of diabetes mellitus in the pre-insulin era (1914-1922). Perspect Biol Med 49: 77-83.

15. Davenport HW (1999) Not Just Any Medical School: The Science, Practice, and Teaching of Medicine at the University of Michigan. Ann Arbor: University of Michigan Press 2: 1850-1941.

16. Newburgh LH, Marsh PL (1920) Use of a High Fat Diet in the Treatment of Diabetes Mellitus: First Paper Arch Inter Med 26: 647.
17. Rand WM, Pellett PL, Young VR (2003) Meta-analysis of nitrogen balance studies for estimating protein requirements in healthy adults. Am J Clin Nutr 77: 109-127.

18. Newburgh LH, Marsh PL (1921) The Use of a High Fat Diet in the Treatment of Diabetes Mellitus: Second Paper. Blood sugar Arch Inter Med 27: 699-705.

19. Marsh PL, Newburgh LH, Holly LE (1922) The nitrogen requirement for maintenance in diabetes mellitus. Arch Intern Med 29: 97-130.

20. Woodyatt RT (1921) Objects and method of diet adjustment in diabetes. Arch Intern Med 28: 125-141.

21. Wilder RM (1921) High fat diets in epilepsy. The Clinic Bulletin 282: 308 .

22. Wilder RM (1924) 'Optimal' diets for diabetic patients discussion following. JAMA 83: 733-737.

23. Walker HK, Hall WD, Hurst JW, Comstock JP, Garber AJ, et al. (1990) Clinical Methods: The History, Physical, and Laboratory Examinations. Boston. Butterworths 12: 15-20.

24. Marsh PL, Waller HG (1923) The relation between ingested fat and the lipemia of diabetes mellitus. Arch Intern Med (Chic) 31: 63-75.

25. Newburgh LH, Marsh PL (1923) Further observations on the use of a high fat diet in the treatment of diabetes mellitus. Arch Intern Med (Chic) 31: 455-490.

26. Joslin Ep (1928) Ideals in the Treatment of Diabetes and Methods for Their Realization. N Engl J Med 198: 379-382.

27. Feinman RD, Pogozelski WK, Astrup A Bernstein RK, Fine EJ, et al. (2015) Dietary carbohydrate restriction as the first approach in diabetes management: critical review and evidence base. Nutrition Jan 31: 1-13.

28. Newburgh LH (1929) The Dietetic Treatment of Diabetes Mellitus. A Restatement of the Fundamental Principles. Ann Intern Med 2: 645-649.

29. Freyberg RH, Newburgh LH, Murrill WA (1936) Cholesterol content of blood in diabetic patients fed diets rich in fat. Arch Intern Med 58: 589-597.

30. Conn J, Newburgh LH (1937) Hyperglycemia Due to Impaired Hepatic Glycogenesis Exp Biol Med 36: 236-238.

31. Newburgh LH, Johnston MW, Wiley PH, Sheldon JM, Murrill WA (1937) A Respiration Chamber for Use with Human Subject. J Nutr 13: 193-201.

32. Newburgh LH, Conn JW (1939) A new interpretation of hyperglycaemia in obese middleaged persons. JAMA 112: 7-11.

33. Newburgh LH (1942) Control of the hyperglycemia of obese "diabetics" by weight reduction. Ann Intern Med 17: 935-942.

34. Taylor R (2013) Type 2 diabetes: etiology and reversibility. Diabetes Care 36: $1047-1055$

35. Himsworth H (1936) Diabetes mellitus: a differentiation into insulinsensitive and insulin-insensitive types. Lancet 1: 127-130.

36. Garg A, Bantle JP, Henry RR, Coulston AM, Griver KA, et al. (1994) Effects of varying carbohydrate content of diet in patients with noninsulin-dependent diabetes mellitus. JAMA 271: 1421-1428.

37. Ratner H, Smith-Ratner D (1994) Varying carbohydrate intake in NIDDM. JAMA 272: 1817-1818. 